\title{
Vibrodiagnostics Used for Evaluating the Technical Condition of a Mechanical Gearbox
}

\author{
Jan Furch ${ }^{1}$, Jiří Stodola ${ }^{2}$ and Josef Glos $^{3}$ \\ ${ }^{1}$ University of Defence, Faculty of Military Technology, Kounicova 65, 66210 Brno, Czech Republic \\ ${ }^{2}$ University of Defence, Faculty of Military Technology, Kounicova 65, 66210 Brno, Czech Republic \\ ${ }^{3}$ University of Defence, Faculty of Military Technology, Kounicova 65, 66210 Brno, Czech Republic
}

\begin{abstract}
The aim of this article is to evaluate the technical condition of a mechanical four-speed gearbox tightly connected to a mechanical two-speed auxiliary gearbox placed in an off-road vehicle. When observing the technical condition of the mechanical gearbox, we used one of technical diagnostics methods, namely vibrodiagnostics. The mechanical gearbox was monitored during all its life cycle up to failure occurrence. In the article there is a detailed description of the stand where the gearbox technical condition was monitored. When observing vibration signals, we used four tri-axial sensors placed in four selected spots depending on the design arrangement of antifriction bearings. In order to evaluate the measured results, two methods were applied, namely the root mean square gRMS based on the measured acceleration in three axes. The other method used for monitoring the technical condition was the Crest factor. The aim of the experiment was to monitor the technical condition of the mechanical gearbox, mainly its antifriction bearings, therefore the values were measured when the gear was put into fourth position and into overdrive in the auxiliary gearbox. When the gear is put into fourth position, the torque is transmitted from the motor through the main gearbox and the auxiliary gearbox directly. Single gearbox wheels are engaged but not loaded (they do not transmit the torque). At the end of our article we introduced the measured values along with the oral evaluation of the technical condition of the mechanical gearbox and the auxiliary gearbox.
\end{abstract}

\section{Introduction}

Vibrodiagnostics is one of the most important methods used for identifying a technical condition. With the use of vibration diagnostics we are able to detect an incipient failure, locate the place of an incipient failure and predict the length of time during which a device is going to work before a failure occurs or a preventive action is performed. The proper application of vibrodiagnostics can prevent undesirable damage to machines, thereby preventing costs associated with repair and wasting money when a device is out of service.

Experimental vibrodiagnostic measurements are performed while obtaining primary signals. Primary results of measurements are systematized and analysed. Operating characteristics of rotary systems with bearings of sliding friction and those of roll are compared. Generalization of research results is done and conclusions are formulated [1], [2], [3]. Advanced computational models suitable for the development of a modern powertrain in the field of noise and vibration are presented in [4].

A lot of companies spend large amounts of money on the preventive maintenance of machines and technical equipment despite the fact that there is no need to take a preventive action at that particular moment. This leads to massive financial losses, mainly during the time the machine is out of service. Therefore, it is desirable to perform preventive maintenance at the time when it is really necessary. A decision on taking a preventive action or replacing a part which is based on the real technical condition is proactive maintenance. This is made possible by using a mathematical model describing the technical condition of a machine during its life. The aim of our paper is to describe the technical condition of the vehicle mechanical gearbox by means of vibrodiagnostics [5].

\section{Possibilities of determining the technical condition of rolling bearings and gearbox wheels}

Vibrations occur as a result of rotating or straight-line moving bodies. The course of vibrations is influenced mainly by the technical condition of individual machine components such as shafts, gear boxes, crank mechanisms, cam mechanisms, antifriction bearings, and also by the imbalance of rotating parts, backlash in friction bearings, wear, material fatigue, cracking phenomenon, corrosion, and other factors affecting the 
smooth running of a machine. The vibration itself is defined then as a dynamic phenomenon when particles or solid bodies move around a zero equilibrium position. Vibrations are given by a combination of six movements, namely by a shift in an orthogonal coordinate system $\mathrm{x}$, $\mathrm{y}, \mathrm{z}$ and by the rotation about these axes. We can describe them by the amplitude and phase in a certain period of time. Depending on the time variations of values, vibrations are of a periodical, non-periodical, or random character. As for periodical vibrations, the course of vibrodiagnostic values keeps repeating over time. Harmonic vibration, which has a sinusoidal waveform, is based on these vibrations. For harmonic vibrations we need to set only one determining value and the others can be calculated.

The basic way of describing oscillations is to determine their displacement $x$, velocity $v$, acceleration $a$, maximum value $A_{\max }$, the root of mean square $R M S$, and the average value $A_{\text {ave }}$ [6].

The International Standards Organization (ISO), which establishes internationally acceptable units for the measurement of machinery vibration, suggested the root mean square (RMS) as the standard unit of measurement. This was decided in an attempt to establish criteria that would determine an effective value for the varying function of acceleration. Acceleration tends to provide the energy content in the vibration signal, whereas the acceleration peak is correlated better with the intensity of vibration [7].

A calculation of the mean value $A_{\text {ave }}$ and root of mean square RMS is based on acceleration, so called effective value $g R M S$. The following formulas were used for the calculation.

Acceleration can be expressed as the characteristics of motion which shows the way the velocity of a body (particle) changes in time. Acceleration is a vector quantity since it gives both the magnitude and direction of the change. It is possible to calculate the instantaneous acceleration and the average acceleration. Acceleration may also be determined as the time derivation of velocity using the formula below [7]:

$a=\frac{d v}{d t}=-X_{\max } \omega^{2} \sin \omega t=X_{\max } \omega^{2} \sin (\omega t+\pi)$

If acceleration is related to a change in velocity in terms of a decreasing speed, it is called deceleration and has a minus sign. The mean absolute value $A_{\text {ave }}$ can be expressed as follows:

$$
A_{\text {ave }}=\frac{1}{T} \int_{0}^{T}|a| d t
$$

The root of mean square can be calculated by the equation below [3]:

$$
g R M S=\sqrt{\frac{1}{T} \int_{0}^{T} a^{2} d t} .
$$

Another parameter used to identify the technical condition of rolling bearings is the Crest factor. The principle of the method is to measure the effective and peak vibration values and their calculation according to the following formula [8]

$$
C=\frac{\left|A_{\max }\right|}{g R M S}
$$

Generally speaking, as any signal exhibits sharpness, its $C$ increases because it would indicate that the peak value is much larger than the $R M S$ value. $C$ is typically used to monitor the change of the signal pattern due to a localized fault such as tooth breakage of a rotating gear which will theoretically generate pulses during meshing. $C$ is also very useful for detecting discrete impulses above the background of the signal, which do not occur frequently enough or have a very short duration to significantly increase the $g R M S$ value. The value of $C$ is in the range of 2.5 to 3.5 is not uncommon for many machines, but in many cases, if its value is 5 or more, it may indicate a problem [8].

\section{Description of the experiment}

The measurement was performed on a testing stand shown in Figure 1. The main parts of the stand are a frame for anchoring measured equipment, a notebook with software DEWESOFT X2 (1), control unit for break AHB12 (2), measuring equipment DEWE-50USB2-8 (3), a frequency converter MOVITRAC MCLTE B0040-5A3-4-00 (4), an asynchronous motor with engine speed control in $10-3000$ RPM (5), a propeller shaft with a flange (6), gearbox with transfer box including four tri-axial acceleration sensors KS943B.100 (7), and air cooled brake AHB/12 (8).

For the measurement itself, we used the DEWE-50USB2-8 device from the DEWETRON firm. This is an 8 -channel device intended for measuring vibrations of equipment. The vibration signal was measured by four KS943B.100 tri-axial accelerometers by which it was possible to measure the vibrations of four places at the same time. Because 12 measuring channels are needed, we use two devices connected in series. These accelerometers were mounted on the gearbox by means of a magnet.

Legend: 1 - Laptop with DEWE software; 2 - Control unit for

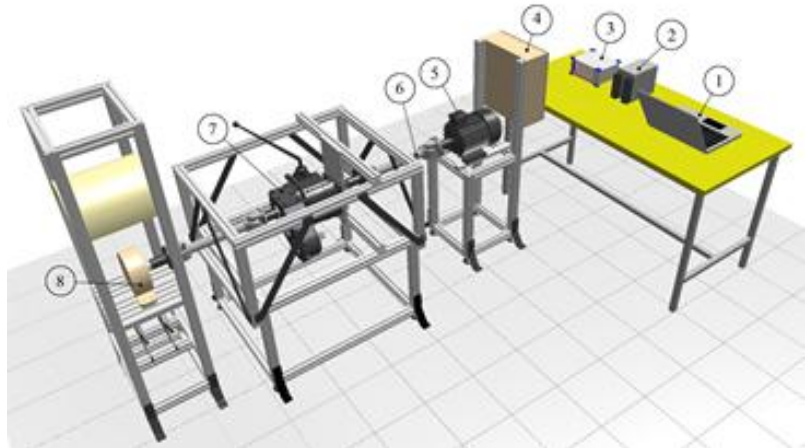

break AHB12; 3 - DEWE-50-USB2-8; 4 - Speed control panel; 5 - Electric motor; 6 - Cardan shaft; 7 - The gearbox with transfer box; 8 - Air-cooled brake AHB-12.

Figure 1. Testing stand for vibration measurements

The aim of this article is to determine the predicted time (detection of potential failure), it is necessary to determine the cause of incipient failure. This is presented in Figure 1. Only then will it be determined whether the 
failure occurred in a roller element, the inner, the outer ring and the cage of roller bearing or in the gear tooth. This is based on the assumption that each part listed above is of a different relative speed to the shaft and of a different frequency at which the failures occur.

\section{Analysis of measurement results}

The experiment was conducted to measure mechanical gearbox (a gear box and a transfer box) durability at input revolutions $2000 \mathrm{rpm}$. During this experiment the mechanical gearbox operated for 3613 hours which is equivalent to $160000 \mathrm{~km}$ of a given vehicle. During all this experiment the gears were changed as illustrated in Table 1 . The gears were changed continuously between single measurements which means all speed gears were always selected. The mechanical gearbox was equally worn during the experiment which was one of the basic measuring rules. When performing the experiment, different running resistances were simulated using the Air-cooled brake AHB-12 and a Control unit for the brake AHB12.

When calculating the root mean square values calculated from $g R M S$ and crest factor $C$ acceleration, the input revolutions were $2000 \mathrm{rpm}$, the gear was put into fourth position in the gearbox and into overdrive in the transfer box.

The root mean square $g R M S$ values were calculated in all common axes dimensions $(\mathrm{x}, \mathrm{y}, \mathrm{z})$. After, the $g R M S$ values were summarized in respective axes, and then an average $g R M S$ value was calculated and put in the resulting graph, see Fig. 2. The $g R M S$ values were calculated for all four sensors in single measuring spots as illustrated in Fig. 2.

Table 1. The operating time for each speed gear of the gearbox and transfer box

\begin{tabular}{|c|c|c|c|c|c|}
\hline $\begin{array}{l}\text { Speed gear } \\
\text { in transfer } \\
\text { box }\end{array}$ & $\begin{array}{l}\text { Operating } \\
\text { time (\%) }\end{array}$ & $\begin{array}{l}\text { Speed } \\
\text { gear in } \\
\text { gearbox }\end{array}$ & $\begin{array}{l}\text { Operating } \\
\text { time (\%) }\end{array}$ & $\begin{array}{l}\text { Operating } \\
\text { time } \\
\text { (hour) }\end{array}$ & $\begin{array}{l}\text { Operating } \\
\text { time }(\mathrm{km})\end{array}$ \\
\hline \multirow{4}{*}{ Overdrive } & \multirow{4}{*}{90} & 1 & 5 & 162.6 & 7200 \\
\hline & & 2 & 10 & 325.2 & 14400 \\
\hline & & 3 & 35 & 1138.1 & 50400 \\
\hline & & 4 & 50 & 1625.9 & 72000 \\
\hline \multirow{4}{*}{ Reduction } & \multirow{4}{*}{10} & 1 & 5 & 18.1 & 800 \\
\hline & & 2 & 20 & 73.3 & 3200 \\
\hline & & 3 & 35 & 126.5 & 5600 \\
\hline & & 4 & 40 & 144.5 & 6400 \\
\hline \multicolumn{4}{|c|}{ Total time (T) } & 3613.0 & 160000 \\
\hline
\end{tabular}

Fig. 2 shows that up to about $40000 \mathrm{~km}$ the bearing run-out is likely to occur. The $g R M S$ values gradually increase up to this mileage. This is followed by a period of routine operation up to about $140000 \mathrm{~km}$ during which the $g R M S$ values are more or less constant. After, the technical condition of the mechanical gearbox and single antifriction bearings and gearbox wheels rapidly decreases. When the operation reaches 150000 - 160000 $\mathrm{km}$, bearings no. 4 and 2 are damaged. Bearings no. 1 and 3 are in a state of near failure occurrence.

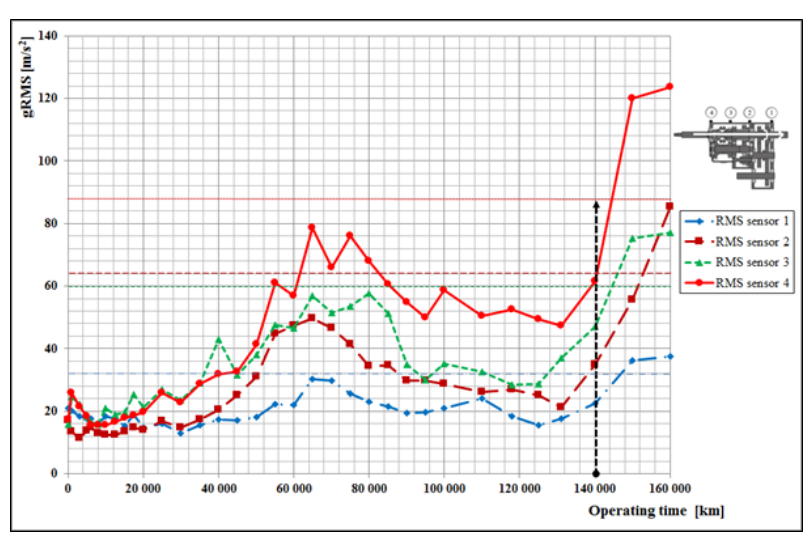

Figure 2. Expressing the dependence of gRMS on mileage the mechanical gearbox

The experiment clearly shows that the measurement can be performed on one box only using more sensors. This applies only when the sensors are properly placed above bearings. First we were afraid that the noise of the box might spread which would result in distorting the measuring results, but fortunately this did not occur

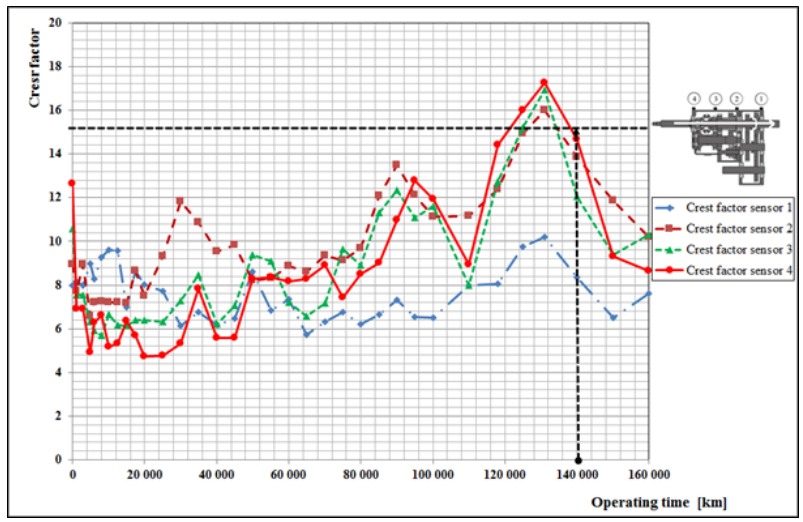

Figure 3. Expressing the dependence of crest factor $C$ on mileage the mechanical gearbox

The crest factor $C$ was used as the other parameter for monitoring the technical condition of the mechanical gearbox. The calculation was performed using the equation (4). In order to calculate the crest factor $C$, we selected the amplitude $A_{\max }$ and the $g R M S$ value in all three axes. These values were summarized and averaged. The results of this experiment are put in Figure 3. The experiment was performed under the same conditions as introduced in the previous part. The measured crest factor $C$ values show that when the operation of a mechanical gearbox reaches about $140000 \mathrm{~km}$, the abnormal wear and then the failure of antifriction bearings occur. The course of crest factor values show that the introduced value $140000 \mathrm{~km}$ is limiting for all four detection spots.

Based on both methods we have come to the conclusion that when the operation of the mechanical gearbox reaches about $140000 \mathrm{~km}$, it is advisable to finish its operation and take appropriate technical measures. 


\section{Conclusion}

The aim of the experiment was to verify that vibrodiagnostics is the proper method used for identifying the technical condition of rotating parts in vehicle mechanical gearboxes. The experiment primarily focused on monitoring the wear of antifriction bearings which are one of the most important parts of a vehicle transmission gear.

The experiment shows us that the vibration signal is an important signal used for identifying the technical condition of rotating parts. When processing the signal, it is essential to select a proper place for sensors, choose appropriate sensors, adjust properly software used for evaluation, introduce the measuring results in the right way, etc. When measuring and analysing, we used Dewesoft hardware and software which turned out to be very suitable. When evaluating the durability of the mechanical gearbox, we used two suitable methods which enabled us to describe the technical condition of antifriction bearings. The first method used for evaluating the technical condition of the mechanical gearbox is the root mean square which helped us to calculate single values put in Figure 2. These values show us that it is possible to determine maximal $g R M S$ values acceptable for single measured spots for a specific gearbox. Based on the introduced results we can conclude that when reaching about $140000 \mathrm{~km}$, the technical condition of antifriction bearings dramatically decreases, and at about $150000 \mathrm{~km}$ the bearings are damaged which was proved after the mechanical gearbox was dismantled. The results achieved by using the other method calculations (crest factor) support the conclusion made when applying the root mean square gRMS method.

\section{Acknowledgment}

Presented work has been prepared with the support of the Ministry of Defence of the Czech Republic, Partial Project for Institutional Development and Specific
Research, Department of Combat and Special Vehicles, University of Defence, Brno.

\section{References}

1. F. Cong, J. Chen, G. Dong, M. Pecht, Vibration model of rolling element bearings in a rotor-bearing system for fault diagnosis. Journal of Sound and Vibration [online]. vol. 332, no. 8, p. 2081-2097, (2013)

2. S. Tsyfanskii, V. Beresnevich, Vibrodiagnostics of fatigue cracks in flexible, geometrically nonlinear, beam-type structural elements. Russian Journal of Nondestructive Testing. pp 427-433, (1994)

3. V. Vekteris, M. Jurevicius, A. Cereska, Vibrodiagnostics of the components of technological machines. 8th International Conference on Vibration Measurements by Laser Techniques Location. Ancona, (2008)

4. P. Novotný, A. Prokop, M. Zubík, K. Řehák, Investigating the influence of computational model complexity on noise and vibration modelling of powertrain. Journal of Vibroengineering. vol. 22, no. 4, p. 277-392, (2016).

5. J. Furch, J. Glos, J. Blecha, Identifying the Technical Condition of Rotating Parts by Means of Vibrodiagnostics. Transaction of Famena. vol. 39, no. 2, pp. $75-86,(2015)$

6. J. Furch, J. Glos, T. T. Nguyen, Identification of the technical condition of roller bearings by means of vibrodiagnostics and tribodiagnostics. Transaction of Famena. vol. 41, no. 3, pp. 99 - 113, (2017)

7. P. Girdhar, C. Scheffer, Practical machinery vibration analysis and predictive maintenance. Burlington: Newnes, 255 p., (2004)

8. M. P. Norton, D. Karczub, Fundamentals of Noise and Vibration Analysis for Engineers. Cambridge University Press, 631 p., (2003) 